"This is the peer reviewed version of the following article: "Changes in Income Distributions and the Role of Tax-benefit Policy During the Great Recession: An International Perspective", which has been published in final form at "Changes in Income Distributions and the Role of Tax-benefit Policy During the Great Recession: An International Perspective", in Fiscal Studies, Vol. 38, Issue 4, December 2017, pp. 559-585, https://doi.org/10.1111/1475-5890.12113. This article may be used for non-commercial purposes in accordance with Wiley Terms and Conditions for Self-Archiving." 


\title{
Changes in Income Distributions and the Role of Tax-benefit Policy During the Great Recession: An International Perspective *
}

\author{
Olivier Bargain, Tim Callan, Karina Doorley and Claire Keane
}

October 23, 2015

\begin{abstract}
This paper examines the impact of the economic crisis and the policy reaction on inequality and relative poverty in four European countries, namely France, Germany, the UK and Ireland. The period examined, 2008 to 2013, was one of great economic turmoil, yet it is unclear whether changes in inequality and poverty rates over this time period were mainly driven by changes in market income distributions or by tax-benefit policy reforms. We disentangle these effects by producing counterfactual ("no reform") scenarios using tax-benefit microsimulation and representative household surveys for each country. For the first stage of the Great Recession, we find that the policy reaction contributed to stabilizing or even decreasing inequality and relative poverty in the UK, France and especially in Ireland. Market income changes nonetheless pushed up inequality and relative poverty in France. Relative poverty increased in Germany due to policy responses combined with market income changes. Subsequent policy reforms, in the later stage of the crisis, had markedly different cross-country effects, decreasing overall poverty in France, increasing it in Ireland and giving mixed effects for different sub-groups in Germany and the UK.
\end{abstract}

Key Words: Tax-benefit policy; Inequality; Poverty; Decomposition; Microsimulation; Crisis.

JEL Classification: H23 $\cdot$ H53 $\cdot$ I32

* Bargain is affiliated to Aix-Marseille University (Aix-Marseille School of Economics), CNRS \& EHESS and IZA, Callan is affiliated to the ESRI, TCD and IZA, Doorley is affiliated to LISER and Keane is affiliated to the ESRI and TCD. We are grateful to the Observatoire National de la Pauvreté et de l'Exclusion Sociale (ONPES) for financial support. We are indebted to the EUROMOD consortium for the use of the model (version G2.0). EU-SILC was made available by Eurostat and the FRS by the UK ONS through the Data Archive. Material from the FRS is Crown Copyright and is used by permission. The usual disclaimer applies. Corresponding author: Tim Callan, tim.callan@esri.ie

This article has been accepted for publication in Fiscal Studies and undergone full peer review but has not yet been through the copyediting, typestting, pagination and proofreading process, which may lead to differences between this version and the Version of Record. Please cite this article as an 'Accepted Article', doi: 10.1111/1475-5890.12113.

This article is protected by copyright. All rights reserved. 


\section{Introduction}

The Great Recession intensified pressure on tax-benefit systems to become more cost effective, to minimise welfare losses and to limit the spread of deep poverty at a time of cuts in public spending. There are lessons to be learned from the ways in which countries responded over this period. As yet, little is known about the capacity of existing redistribution systems to soften the negative impacts of job and earnings losses, as well as the effectiveness of the policy initiatives that quickly followed the onset of the economic slump. This is not only due to the fact that microdata come with an inevitable delay but also because the different factors affecting the distribution of disposable income are intertwined. ${ }^{1}$ In particular, analysts should attempt to disentangle the effect of changes in market income inequality (due to wage cuts, job losses or working time reduction in the private sector, changes to the minimum wage etc.) and the effect of tax-benefit reforms. The latter may indeed have cushioned or exacerbated the effects of the crisis on the income distribution through income tax and social insurance reforms, changes in the generosity of family benefits or welfare programs, etc. Comparing European experiences in this context also seems highly relevant. The effects of each of these factors may have been different across countries depending on how deeply they were affected by the crisis and on the specific nature of the policy responses.

A small body of literature has begun to address these questions. The study of Jenkins et al. (2013) examines the short-term impact of the Great Recession in twenty-one OECD countries, finding that the household sector was largely protected from the downturn through the tax and benefit system. Another related study by Brewer et al (2013) looks at the past and projected policy response of the UK to the crisis. Findings suggest that most of the pain of the recession was felt by households during and after 2010. Matsaganis and Leventi (2014) addressed the cushioning effect of tax-benefit systems in southern and eastern european countries during the crisis. Lastly, De Agostini et al (2014) study the effect of policy changes between 2008 and 2013 on income distributions in a number of EU countries, finding broadly progressive effects.

In this paper, we provide further answers to these questions by studying the joint contribution of tax-benefit policies and market income shocks to changes in inequality and poverty in a selection of European countries between 2008 and 2013. We proceed by pro-

\footnotetext{
${ }^{1}$ For instance, an approach that consists of measuring the contribution of taxes and transfers to overall inequality/poverty at different points in time, e.g. before and after the onset of the Great Recession, does not allow us to extract the pure effect of policy changes from their interaction with the underlying population. That is, this method cannot tell whether social assistance schemes, for example, may appear more redistributive because of their increased generosity or because of automatic increases in welfare spending as unemployment rises.
} 
viding two decompositions of the disposable income distribution: (i) a full decomposition of the income distribution between 2008 and 2010 into a policy and market income effect and (ii) a partial decomposition of the income distribution between 2010 and 2013, identifying a policy effect alone. ${ }^{2}$ In this way, we are able to quantify the relative importance of market income and policy changes in overall changes to the income distribution. We use tax-benefit microsimulation to construct counterfactual situations that show what the post-tax and transfer income distribution would have looked like in 2013 (and 2010) if either tax-benefit policies or the distribution of pre-tax and transfer incomes had remained unchanged from 2010 (2008). In this way, we are able to disentangle the pure effect of tax-benefit policy changes occurring over the period 2008-2010 from changes in the environment in which these policies operate, particularly changes in market income inequality which may have occurred due to job losses or wage cuts. ${ }^{3}$ We also present the policy effect of changes occurring between 2010 and 2013. This analysis is carried out for four European countries which were affected differently by the economic crisis, namely France, Germany, Ireland and the UK. For each country, we isolate and quantify the effect of tax-benefit policy changes between 2008 and 2013 on a range of poverty and inequality measures. We use representative microdata for each country from the beginning of the economic crisis (2007/2008) and from the latest period available (2009/2010), coupled with microsimulation models (SWITCH for Ireland and EUROMOD for France, Germany and the UK), i.e. models that transform gross income into disposable income for each household, taking into account taxes, transfers and contributions in each period and country. Using these simulations, we can draw conclusions about the effect of the economic crisis on poverty and inequality across countries as well as the effectiveness of tax-benefit policies in responding to the economic crisis in each country.

We find that Ireland, despite being the country hardest hit by the recession, experienced no real change in inequality and a decline in relative poverty rates between 2008 and 2010 due to the strongly progressive policy response. The policy response offset the rise in inequality and child poverty which would have otherwise arisen from changes in unemployment and market income in the early part of the recession. The policy impact of changes made between 2010 and 2013 in Ireland have, however, worked in the oppo-

\footnotetext{
${ }^{2}$ Due to data constraints, discussed later in the paper, we are unable to provide the full decomposition up to 2013.

${ }^{3}$ This approach is applied in the study of Clark and Leicester (2004) who investigate the distributional effect of policy changes over the 1980s and 1990s in the UK. It is then embedded in a more formal decomposition framework in Bargain and Callan (2010) for France and Ireland and Bargain (2012) for the UK for the period 1999-2001. A related concept for the comparison of tax regimes with respect to progressivity, the transplant-and-compare procedure (Dardanoni and Lambert 2002), is applied by Lambert and Thoresen (2009) for Norway. They isolate the tax policy effect by comparing pre-tax income distributions which have been adjusted to a common base.
} 
site direction and have caused a small increase in inequality and a substantial increase in poverty rates. Germany the country least affected by the recession, saw a rise in the poverty rate and depth between 2008 and 2010, driven largely by policy effects. The policy changes implemented between 2010 and 2013 have continued to push up poverty rates of certain groups, including those in employment. Overall the increase in poverty rates in Germany between 2008-2013 is due to a combination of regressive tax policy and slow uprating of social benefits for the poorest. Between 2008 and 2010, France saw a rise in inequality and the poverty rate, due mainly to non-policy effects such as job losses and wage cuts. The same period in the UK saw reductions in inequality and poverty which are attributable to policies such as tax cuts and benefit increases. Policy changes during the 2010-2013 period resulted in mixed results for different groups in the UK while, in France, policy changes during this time period reduced poverty and inequality.

The paper is laid out as folows. Section 2 examines the macroeconomic and policy background of the four countries, detailing the main policy changes made since the onset of the resession. Section 3 describes the methodology, data and tax-benefit models used. Section 4 presents the results, while section 5 concludes.

\section{Macroeconomic and Policy Background}

\subsection{Welfare Regimes before the Crisis and the Macroeconomic Context}

Our study presents an original perspective by comparing trends in income distributions and policy developments in four European countries which have been impacted differently by the crisis. In the year preceding the crisis, all four countries were relatively close in terms of GDP per capita. ${ }^{4}$ France and Germany used to be classified under the conservative/corporatist welfare regime (Esping-Andersen 1990) while the UK represented a more liberal model, although some nuance is required. Despite low income tax rates, the UK offers a safety net in the form of income support schemes and a relatively generous family tax credit for working poor families and for families with children, regardless of their employment status. In parallel, France and Germany have experienced a significant cut in tax levels since the early 2000s while introducing or increasing transfers to the working poor. In Germany, wage moderation and reforms of the social system in the early 2000s

\footnotetext{
${ }^{4}$ In 2007, France, Germany and the UK were 8\%, $16 \%$ and $17 \%$ above the EU-27 average GDP per capita respectively while Ireland was $46 \%$ above the average. Repatriation of multinational profits from Ireland, however, means that GNP was about $80 \%$ of the level of GDP, providing a better measure of the national income available to Irish residents - more comparable to that of our three other countries.
} 
may also have had some regressive impact on the distribution of income but there is no substantial evidence of this. Ireland was traditionally placed at a somewhat intermediary position, with a social protection system described sometimes as "catholic corporatist" (McLaughlin, 1993), due to the role of the Church and the central role of the family, or as competitive corporatist since transfers, taxation and labour market institutions were broadly adapted to competitiveness objectives (Hardiman 2000).

The economic evolution observed in these countries during the crisis is particularly contrasted, ranging from the German employment "miracle" (still accompanied by wage moderation) to a strong negative adjustment in the Irish economy, with the UK and France performing somewhere in between. We describe the macroeconomic context in detail below. The importance of automatic stabilizers and discretionary fiscal policy in each country will also, ultimately, determine the extent to which the Great Recession affected overall poverty and inequality measures during this timespan. Policy options in each country are described in the next sub-section.

Germany experienced a strong macro shock in 2008-09 (-4.9\% in real GDP) but a return to positive growth of over $4 \%$ in 2010 as shown in Figure 1, largely due to strong global demand for German exports (Jenkins et al, 2013). The use of short-time work in particular has prevented an increase in unemployment and, according to Bargain et al. (2012), has partly (fully) limited the increase in relative (absolute) poverty. Unemployment rates in Germany and France prior to 2008 were generally higher than those in Ireland and the UK, as shown in Figure 2. German unemployment rates resumed falling after 2009, reaching their lowest level in recent decades (5.5\% in 2012). ${ }^{5}$ France was less internationally exposed than other countries like Germany due to a traditionally strong reliance on its internal market. The macro shock was therefore slightly smaller $(-3.7 \%$ of GDP in 2009) but so was the return to growth in $2010(+1.1 \%)$. This was accompanied by a long-lasting deterioration of labour market conditions (Figure 2), showing an increase in unemployment from a low of $7.8 \%$ in 2008 to $10.3 \%$ in 2013 . The period 2008 to 2010 saw a recession of unprecedented severity in the Irish economy. GDP had grown strongly over the preceding 15 years, with employment almost doubling and unemployment rates falling sharply (Figure 2). During this 'Celtic Tiger' period, unemployment fell to just over $4 \%$ in 2000 and remained around this level until 2008. Over the years 2008 to 2010, real national income fell by close to $10 \%$ - more than double the size of the fall in the UK, Germany and France. The economic deterioration was driven by a collapse in the

\footnotetext{
${ }^{5}$ Burda and Hunt (2011) attribute this 'unemployment miracle' to a variety of factors such as employers reticence to hire in the preceding expansion, wage moderation and an increased adoption of 'working time accounts'. Brenke et al. (2011) also give credit to the expansion of the short-term compensation scheme, which provides financial aid for firms experiencing difficulties if they agree to reduce working hours and pay, describing it as the 'German answer' to the great recession.
} 
property sector and an accompanying sharp fall in employment in the construction sector, upon which the Irish economy had become heavily reliant, a banking crisis and the worldwide financial crisis. ${ }^{6}$ Unemployment more than doubled between 2008 and 2011, increasing from $6.4 \%$ in 2008 to $14.7 \%$ in 2010 . The UK, fuelled by the global financial crisis, also entered its deepest recession since the Second World War in 2008. Significant falls in real GDP were experienced between 2008 and 2010 with a decline of $1.6 \%$ in 2008 and $4.6 \%$ in 2009 , followed by a return to positive growth in 2010 of $1 \%$. A weak recovery was followed by the first double-dip recession in the UK since the 1970s as a return to negative growth occurred in 2012. Unemployment rose from $5.6 \%$ in 2008 to $8.1 \%$ in 2011, after which it began to fall.

Figure 1: GDP per capita Growth Rate, 1996-2012
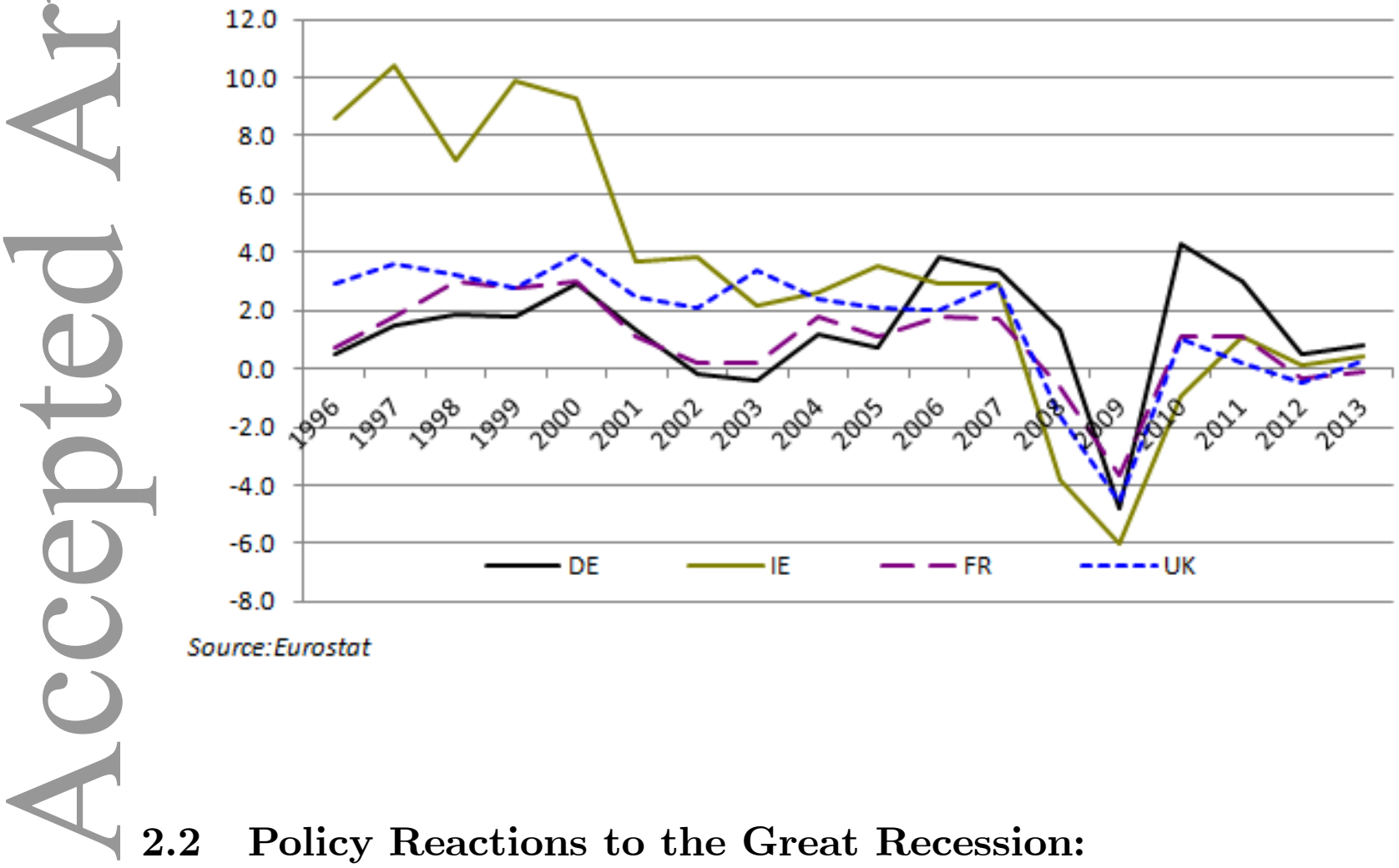

Source:Eurostat

\subsection{Policy Reactions to the Great Recession:}

Our decomposition analysis identifies "policy effects" between 2008 and 2013 and "other effects" between 2008 and 2010. By "policy effect", we mean the effect of changes in tax-

\footnotetext{
${ }^{6}$ The banking crisis resulted in the government guaranteeing both investors and bondholders and led to unsustainable yields on Irish bonds as government debt grew. These unsustainable yields led to the Irish government seeking a financial 'bailout' from the ECB and IMF in 2010. Firm commitments to fiscal austerity formed part of the terms of the economic adjustment package, with further negative consequences for household disposable incomes (see Doorley et al, 2013).
} 
Figure 2: Unemployment Rates, 2005-2012

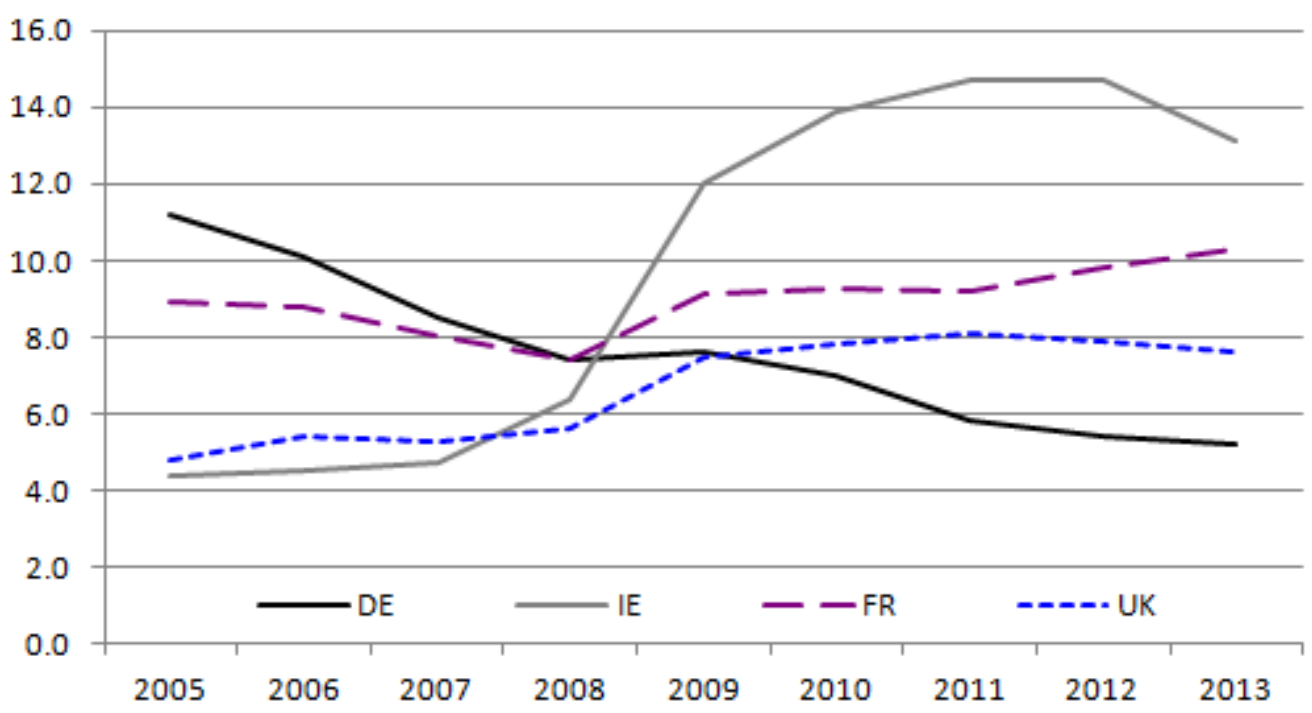

Source:Eurostat

benefit policies ${ }^{7}$ related to direct taxation, social security contributions, non-contributory benefits (child and family benefits as well as social assistance) and contributory benefits which are treated as redistribution (essentially Jobseeker's allowances and public pensions). The set of tax-benefit policies which are actually simulated in our analysis and which constitute the scope of our "policy effect" is presented in Table A.1 in the Appendix. By "other effects", identified only for the period 2008-2010, we mean all the other factors that can affect the distribution of disposable income: these are primarily changes in gross incomes due to market forces but they also account for other policies (changes in the minimum wage, changes in unemployment benefit or pension rules in France and Germany, etc.). We present the main policy changes characterizing the period for which a full decomposition is possible, 2008-2010 (Phase 1). We also describe the main policy changes occurring in the time period for which only a "policy effect" can be obtained due to data restrictions, 2010-2013 (Phase 2) ${ }^{8}$ Tax-benefit policy changes in all four countries are summarized in Table 1 . This table also shows changes in minimum and average wages between 2008-10 and 2010-13 as well as changes in inflation to allow us to determine if increases in tax and social insurance thresholds along with benefit rates kept pace with

\footnotetext{
${ }^{7}$ For Ireland, changes to public sector wages are also counted in our 'policy effect'.

${ }^{8}$ For more information on policy reforms during the period under study, see Doorley (2013) for France, Ochmann and Fossen (2013) for Germany, Doorley et al. (2013) and Callan et al (2012) for Ireland and Sutherland (2013) for the UK.
} 
wage and price inflation. The mean wage changes $\left(\alpha^{1}\right.$ and $\left.\alpha^{2}\right)$ reported in Table 1 will be used to uprate tax-benefit systems and income distributions, as described in Section 3.

The main policy changes enacted over the period 2008-2013 in the four countries studied are as follows. ${ }^{9}$ France saw the addition of an in-work benefit scheme (RSA) to its minimum income policy (RMI) in 2009. Family benefits, social assistance and the earned income tax credit progressed at a slower rate than income or price growth between 2008-10. Social assistance and the earned income tax credit continued to progress slower than income between 2011-13 while family benefits had caught up with income growth by 2013. Progressive tax reforms dominated the period with increases in the level of capital and income tax rates, particularly for the highest earners. In Germany, tax allowances for the elderly were steadily reduced between 2008 and 2013. Social assistance payments grew slower than income between 2008 and 2010 but had caught up by 2013. In a structural reform, the lowest income tax rate was reduced in 2009. From 2011 onwards in Germany, tax and social security bands grew slower than income while child benefits grew faster than income. Ireland implemented a strong set of austerity measures between 2008-10 including income tax increases, reductions in child benefit and social assistance and public sector pay cuts. 2011 onwards saw further austerity measures in the form of reductions of income tax bands and tax credits, increases in social security payments, further decreases in social assistance and child benefit and the introduction of a property tax. The UK policy changes between 2008-10 included increases in income tax rates, especially for high earners as well as redistribution towards the working poor through an increase in the working tax credit. Increases in the child tax credit also occurred during this period. From 2011 onwards, child benefit was withdrawn from high earners and the working hours required to claim the working tax credit increased. The highest rate of income tax was reduced in 2013 .

It is useful to look at the extent of policy changes that were implemented between 2008 and 2010, the years of our full decomposition, compared to the extent of policy changes implemented over the whole period. This exercise gives us an idea of the degree to which our Phase 1 decomposition captures policy reactions to the recession. Looking at Table 1, we note that while many structural reforms were implemented in France between 2008 and 2010, such as the extension of the minimum income to the working poor, more were implemented in the following three years, such as the introduction of new income tax bands for high earners. For Germany, there were no major structural reforms after 2010 although tax allowances for the elderly continued to decrease. Rather we see higher uprating of transfers and a stagnation of tax and social security thresholds in Germany after 2010. In the UK, one of the major austerity measures was relaxed in Phase 2 with

\footnotetext{
${ }^{9} \mathrm{~A}$ full description of these changes is available in Appendix A.2.
} 
Table 1: Description of Tax-Benefit Policy Changes between 2008-2010 and 2011-2013

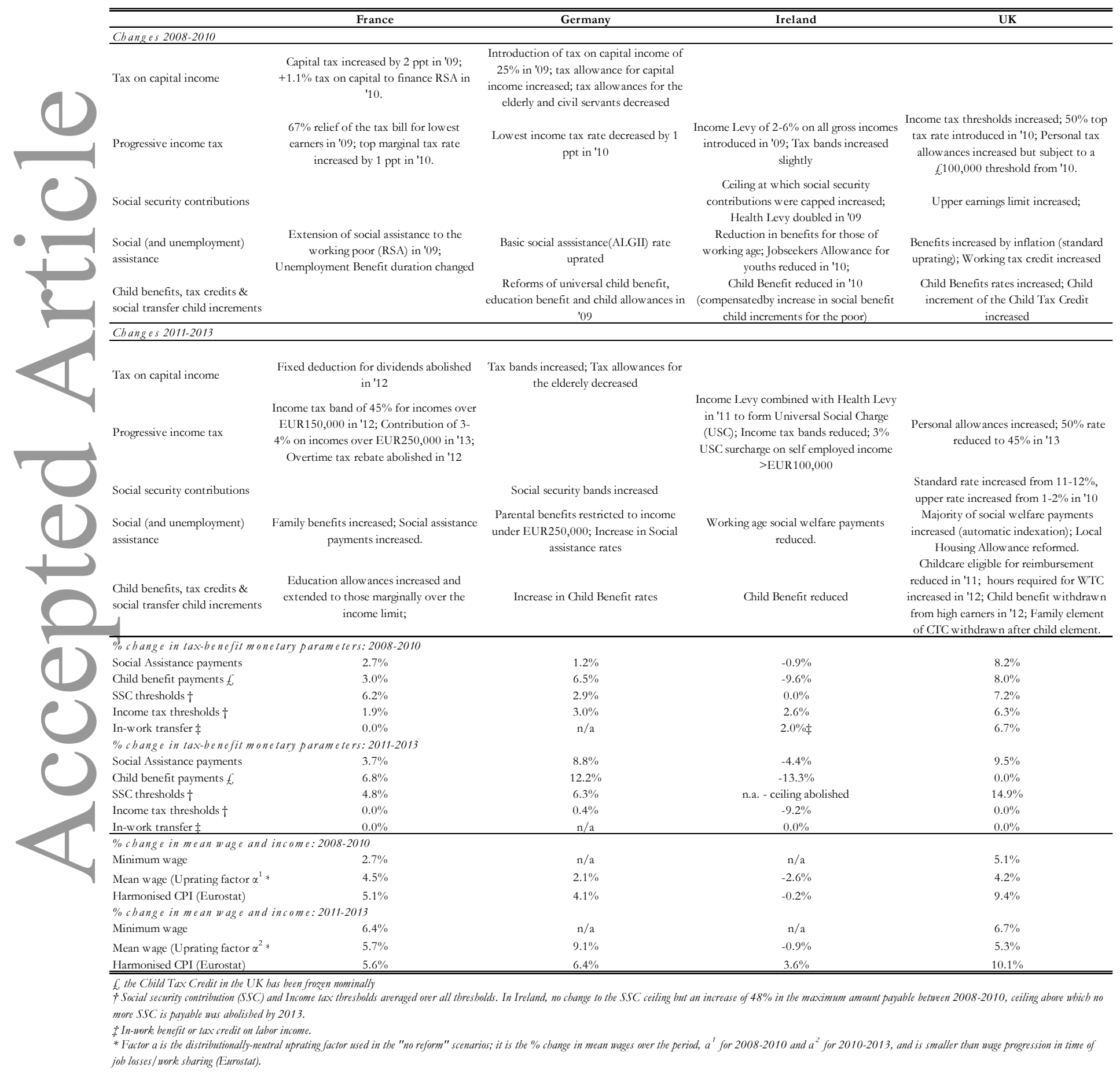


the top tax rate of $50 \%$, introduced in 2010, reduced to $45 \%$ in 2013. Structural tax changes implemented in Ireland during Phase 1 tended to be extended in Phase 2 while decreases in monetary tax and transfer parameters began or continued to decrease beyond 2010. This illustrates the importance of policy reforms after 2010 to overall recovery and highlights the need to examine the 'policy effect' from 2010 to 2013.

\subsection{Aggregate Changes in Incomes, Taxes and Benefits}

Table 2 shows mean household gross income, taxes, transfers, social security contributions (SSC) and disposable income for the four countries investigated. These statistics give some preliminary insight into potential tax-benefit policy effects on household disposable income. We present the percentage change between 2008 and 2010, the years of our full decomposition. We also show the percentage change that occurred between 2010 and 2013. As we do not yet have data for 2013, the disposable income distribution for this year is obtained by applying the 2013 tax-benefit rules to 2010 data with incomes uprated by 2010-13 wage growth ( $\alpha^{2}$ from Table 1 ). Therefore, the latter figures should be interpreted with caution as they take no account of demographic or market income changes between 2010 and 2013.

Gross income between 2008 and 2010 increases slightly in France and Germany, decreases slightly in the UK and decreases significantly in Ireland. Disposable income increases in France, Germany and the UK while in Ireland, it decreases less rapidly than gross income. The main reason for these phenomena is the stabilizing effect of tax-benefit systems over the 2008-2010 period, i.e a decrease in market income for some households is partly compensated by an automatic decrease (increase) in taxes paid (benefits received). On top of this stabilization provided by the initial policy set, there may be also the specific effect of policy changes over the period, the role of which is investigated in the rest of this paper. We can already comment on this using trends in tax and benefit aggregates in Table 2. Yet we must keep in mind that these trends between 2008-2010 combine the stabilization effect (how taxes paid and benefits received vary due to changes in market incomes) and the effect of policy reforms during the period. Tax changes in Germany and France in the first period seem regressive. In particular, in Germany, the tax bill falls substantially $(-9 \%)$, likely to be partly due to the decrease in the lowest tax rate previously described. Conversely, tax payments increase in Ireland between 2008-2010, following the exceptional measures described above and, in particular, the introduction of an "Income Levy" on all gross incomes. Social security contributions in Ireland also increase substantially between 2008-2010 as the ceiling above which contributions were capped rose. In France (and the UK), the transfer system contributes most to the increase in disposable income with households receiving an average of $12 \%$ (11\%) more in transfers 
in 2010 compared to 2008, probably influenced by the uprating of social transfers and tax credits and the introduction of an in-work transfer, the RSA, in France as described above. A similar and even stronger redistributive effect can be observed for Ireland, with a $15 \%$ increase in transfers between 2008 and 2010, partly cushioning the dramatic decrease in mean gross income. Policy changes on the benefit side are more modest in Germany, with transfer payments increasing by less than $1 \%$ over the period. Again, these trends combine the interaction of existing policies with changes in market income, together with genuine tax-benefit policy reforms over the period. The decomposition approach suggested hereafter allows us to disentangle these two factors.

Table 2: Mean Household Income, Taxes and Transfers

\begin{tabular}{|c|c|c|c|c|c|c|c|c|c|c|}
\hline & \multicolumn{5}{|c|}{ France } & \multicolumn{5}{|c|}{ Germany } \\
\hline & 2008 & 2010 & $\begin{array}{c}\% \Delta \\
08-10\end{array}$ & 2013 & $\begin{array}{l}\% \Delta \\
10-13\end{array}$ & 2008 & 2010 & $\begin{array}{c}\% \Delta \\
08-10\end{array}$ & 2013 & $\begin{array}{c}\% \Delta \\
10-13\end{array}$ \\
\hline Gross income & 2,886 & 2,889 & $0.1 \%$ & 3,055 & $5.7 \%$ & 2,679 & 2,710 & $1.2 \%$ & 2,958 & $9.1 \%$ \\
\hline Taxes & 515 & 497 & $-3.6 \%$ & 621 & $25.1 \%$ & 584 & 534 & $-8.6 \%$ & 621 & $16.3 \%$ \\
\hline Transfers & 1,093 & 1,225 & $12.1 \%$ & 1,287 & $5.1 \%$ & 1,024 & 1,031 & $0.7 \%$ & 1,107 & $7.4 \%$ \\
\hline Employees' contr. & 294 & 253 & $-13.7 \%$ & 315 & $24.3 \%$ & 467 & 486 & $4.0 \%$ & 530 & $9.1 \%$ \\
\hline Self-employed contr. & 64 & 62 & $-2.6 \%$ & 70 & $11.7 \%$ & 35 & 29 & $-18.1 \%$ & 31 & $8.8 \%$ \\
\hline Disposable income & 3,105 & 3,302 & $6.3 \%$ & 3,336 & $1.0 \%$ & 2,617 & 2,693 & $2.9 \%$ & 2,882 & $7.0 \%$ \\
\hline \multirow[t]{3}{*}{ No. of households } & 10,418 & 11,042 & & 11,042 & & 13,312 & 13,079 & & 13,079 & \\
\hline & \multicolumn{5}{|c|}{ Ireland } & \multicolumn{5}{|c|}{ UK } \\
\hline & 2008 & 2010 & $\begin{array}{c}\% \Delta \\
08-10\end{array}$ & 2013 & $\begin{array}{c}\% \triangle \\
10-13\end{array}$ & 2008 & 2010 & $\begin{array}{c}\% \Delta \\
08-10\end{array}$ & 2013 & $\begin{array}{l}\% \triangle \\
10-13\end{array}$ \\
\hline Gross income & 3,383 & 3,008 & $-11.1 \%$ & 2,978 & $-1.0 \%$ & 2,637 & 2,631 & $-0.2 \%$ & 2,767 & $5.2 \%$ \\
\hline Taxes & 466 & 499 & $7.0 \%$ & 602 & $20.8 \%$ & 564 & 567 & $0.6 \%$ & 563 & $-0.8 \%$ \\
\hline Transfers & 1,022 & 1,179 & $15.3 \%$ & 1,108 & $-6.0 \%$ & 707 & 783 & $10.8 \%$ & 791 & $0.9 \%$ \\
\hline Employees' contr. & 93 & 158 & $69.2 \%$ & 66 & $-58.4 \%$ & 186 & 188 & $0.9 \%$ & 195 & $4.1 \%$ \\
\hline Self-employed contr. & 21 & 29 & $41.0 \%$ & 11 & $-63.3 \%$ & 13 & 12 & $-3.4 \%$ & 14 & $11.4 \%$ \\
\hline Disposable income & 3,823 & 3,537 & $-7.5 \%$ & 3,437 & $-2.8 \%$ & 2,581 & 2,647 & $2.5 \%$ & 2,785 & $5.2 \%$ \\
\hline No. of households & 5,247 & 4,642 & & 4,642 & & 25,088 & 25,200 & & 25,200 & \\
\hline
\end{tabular}

Monetary values are in Euros (transformed using the 2010 exchange rate for the UK). German and French results from 2008, 2010 and 2013 Euromod systems used with 2008 and 2010 EU-SILC data. UK results from Euromod 2008, 2010 and 2013 systems using 2008/9 and 2009/10 FRS data. Irish results from SWITCH 2008, 2010 and 2013 using 2008 and 2010 EU-SILC data

Recall that the percentage change between 2010-2013 in household gross income, taxes, transfers, SSC and disposable income is the change that is attributable to policy only as 
we are working with 2010 data. The full impact on incomes over the 2010-2013 period will, of course, be a combination of policy effects and other changes (market incomes etc) which will only be detected once 2013 data is available. Gross income changes between 20102013 reflect the uprating factor used to convert 2010 monetary values to 2013 levels for use with 2013 policies ( $\alpha^{2}$ from Table 1). Gross income rises in all countries but Ireland which continues to see a (small) decline of 1\%. Transfers rise in Germany and France $(5-8 \%)$ but fall in Ireland $(-6 \%)$ and are stable in the UK. Taxes increase significantly in all countries but the UK. Disposable income rises slightly in France $(+1 \%)$ and more so in Germany $(+7 \%)$ and the UK $(+5 \%)$ but continues to decline $(-3 \%)$ in Ireland as can be expected with a decline in gross income and transfers. As described in Table 1 and Appendix A.3, a component of social insurance, the Health Levy, was removed from the social insurance scheme and combined with the Income Levy in 2011 to form the USC. The USC can be viewed as an additional income tax. This change gives the appearance of a sharp reduction in social insurance charges accompanied by a rise in taxation - the net effect, however, is that total deductions from gross income (taxes plus social insurance) remained roughly unchanged between 2010 and 2013 in Ireland.

\section{$3 \quad$ Methodology}

We use tax-benefit microsimulators linked to household surveys to simulate disposable income distributions and, subsequently, inequality and poverty indices for one year at the onset of the crisis (2008), for an intermediate year based on the availability of the microsimulation models linked to survey data (2010), for an end year for which microsimulation models (without the relevant data) are available (2013) and for counterfactual scenarios as described hereafter.

\subsection{Microsimulation and Data}

Simulations are performed using the tax-benefit calculator EUROMOD for France, Germany and the UK and SWITCH for Ireland. Both of these microsimulation models numerically simulate tax-benefit rules, allowing the computation of all social contributions, direct taxes and transfers to yield household disposable income. Microsimulators are linked to the Family Resources Survey (FRS) for years 2008/09 and 2009/10 for the UK (collected over the twelve months between April and March), to the EU-SILC data for years 2008 (2007 incomes) and 2010 (2009 incomes) for France and Germany (EU-SILC data is collected over the calendar year), and to national SILC data from 2008 (2008 
incomes) and 2010 (2010 incomes) for Ireland. ${ }^{10}$ The income reference period for the German and French EU-SILC data is the previous year so that the 2008 data collects 2007 income and the 2010 data collects 2009 income. We account for this delay by uprating all income sources by income-specific indices in EUROMOD in order to be able to use the 2008 and 2010 policy parameters with the corresponding data for each year.

The major advantage of a microsimulation model is that it allows us to examine possible counterfactual scenarios (e.g. what if tax-benefit policies had simply been indexed by inflation?) and allows us to attribute changes in inequality and poverty to government policy or to market and demographic forces. It is worth noting, however, the standard limitations that accompany the use of microsimulation models. Firstly, the models are static and assume no behavioural response to policy changes. Any behavioural responses occurring between 2008 and 2010 will therefore be picked up in the 'other effects' category. Survey data tends to have issues accurately capturing the higher end of the income distribution. Therefore, we should be wary of measures affected by this such as the Gini coefficient. Take-up of means-tested benefits is generally not $100 \%$ although basic microsimulation of benefits attributes them to all eligible households. We deal with this by introducing random non-take-up to the main means-tested benefits in the four countries studied. In addition to this there may be some policy changes that are not captured by a tax-benefit model due to a lack of information in the underlying data that prevents simulation of a tax or benefit. Indirect taxes are generally not captured in microsimulation models as expenditure information is often not present in the income surveys used to build a database for the tax-benefit model. In France and Germany there were no changes in indirect taxation between 2008 and 2013. In Ireland, changes in VAT were minimal and had little additional impact across the income distribution. In the UK VAT changes were relatively large. The inclusion of VAT in the analysis of UK income distributions in De Agostini et al (2014) alters the magnitude of the changes in income across all income groups with a sharper effect being seen at the poorest income decile. The overall pattern of gains for the bottom eight deciles and losses for the top decile was unchanged, however. Therefore, if we were able to include indirect tax reforms in our analysis, our inequality/poverty measures might be higher than presented here. ${ }^{11}$ A more detailed dis-

\footnotetext{
${ }^{10}$ The FRS is a well-known source for statistical studies in the UK, notably used in national microsimulation (see Sutherland, 2013). EU-SILC (statistics on income and life conditions) constitute the most recent and important source of microdata for comparative studies on income distribution in Europe. Started in 2003 for 6 member states (Belgium, Denmark, Greece, Ireland, Luxemburg and Austria), as well as Norway, EU-SILC has been extended to other EU countries in 2004-2005, followed by Bulgaria, Rumania, Turkey and Swizerland from 2007. It gathers annual cross-sectional information on European individuals and households (incomes, socio-demographics, social exclusion, life condition). It was originally created to provide the material for structural indices of social cohesion in Europe (Laeken indices).

${ }^{11}$ De Agostini et al (2014) also point to the impact of different uprating or indexation factors (e.g.
} 
cussion of these issues can be found in Appendix A.4 in which we compare simulated disposable income distributions with actual distributions (i.e. those from external statistics or directly observed in the data) and discuss the potential discrepancies caused by delayed incomes for these two countries. We also explain in detail how and why simulated inequality and poverty measures differ in levels from observed ones at any point in time. We show nonetheless that they are relatively close in terms of time variation, which is the key aspect for the validity of our analysis.

\subsection{Definitions and the Decomposition Method}

First, it is important to define our terminology and the scope of the policy changes that we intend to characterize in what follows. Our analysis focuses on changes in the distribution of household, equivalized ${ }^{12}$, disposable income. 'Disposable income', as widely used to measure poverty and inequality, is defined as all household incomes net of taxes and social contributions and after receipt of all types of benefits. By household 'gross income' or 'market income', we mean the total amount of labour income, capital income and private pensions before taxes and benefits. ${ }^{13}$

Our decomposition analysis will isolate a "policy effect" from "other effects", for the period 2008-2010 and a "policy effect" alone for the period 2010-2013. For this purpose, we define seven simulated distributions of disposable income in our analysis and these are summarized in Table 3. We introduce some notation to describe the construction of these counterfactuals. Denote $y$ a matrix describing the population contained in the data, i.e., each row contains all the information about a given household, including various market income sources and socio-demographic characteristics. Denote $d$ the 'tax-benefit function' which transforms, for each household, gross incomes and household characteristics into a certain level of disposable income. Tax-benefit calculations also depend on a set of monetary parameters $p$ (e.g., maximum benefit amounts, threshold level of tax brackets, etc.). Thus, the distribution of disposable income is represented hereafter by $d_{i}\left(p^{j}, y^{l}\right)$,

price inflation, wage inflation, total market income inflation, zero indexation) can have on the estimated distributional effects of policy changes. A robustness analysis (result available from authors) in which we use CPI instead of wage growth to uprate parameters and income distributions does not change our conclusions in this paper.

${ }^{12}$ Using the modified OECD equivalent scale.

${ }^{13}$ Replacement incomes (public pensions and unemployment benefits) are considered as transfers in the UK and Ireland because public pensions and unemployment insurance can be viewed as part of the redistributive system (maximum benefit levels are not tied to the amount of past contributions). For France and Germany, pensions and unemployment benefits are insurance mechanisms, with payments closely related to contributions levels. To ease comparison, we treat them as transfers in this analysis but alternative simulations which treat them as replacement incomes do not affect our results. 
for a hypothetical scenario including the population of year $l$, the tax-benefit parameters of year $j$ and the tax-benefit structure of year $i$. We are interested in relative inequality/poverty indices calculated based on the final disposable income for each scenario. Suband super-script 0 in table 3 indicates the year 2008, 1 indicates 2010 and 2 indicates 2013.

Table 3: Summary of Scenarios

\begin{tabular}{cccccccc}
\hline \hline & \multicolumn{4}{c}{ Data } & \multicolumn{5}{c}{ Tax-Benefit Policies } & Notation \\
Scenario & \multicolumn{1}{c}{ Year } & Uprated & Uprated to Year & \multicolumn{2}{c}{ Year } & Uprated & Uprated to Year \\
\hline$(0)$ & 2008 & No & - & 2008 & No & - & $\mathrm{d}_{0}\left(\mathrm{p}^{0}, \mathrm{y}^{0}\right)$ \\
$(1)$ & 2008 & Yes & 2010 & 2008 & Yes & 2010 & $\mathrm{~d}_{0}\left(\alpha^{1} \mathrm{p}^{0}, \alpha^{1} \mathrm{y}^{0}\right)$ \\
$(2)$ & 2010 & No & - & 2008 & Yes & 2010 & $\mathrm{~d}_{0}\left(\alpha^{1} \mathrm{p}^{0}, \mathrm{y}^{1}\right)$ \\
$(3)$ & 2008 & Yes & 2010 & 2010 & No & - & $\mathrm{d}_{1}\left(\mathrm{p}^{1}, \alpha^{1} \mathrm{y}^{0}\right)$ \\
$(4)$ & 2010 & No & - & 2010 & No & - & $\mathrm{d}_{1}\left(\mathrm{p}^{1}, \mathrm{y}^{1}\right)$ \\
$(5)$ & 2010 & Yes & 2013 & 2010 & Yes & 2013 & $\mathrm{~d}_{1}\left(\alpha^{2} \mathrm{p}^{1}, \alpha^{2} \mathrm{y}^{1}\right)$ \\
$(6)$ & 2010 & Yes & 2013 & 2013 & No & - & $\mathrm{d}_{2}\left(\mathrm{p}^{2}, \alpha^{2} \mathrm{y}^{1}\right)$ \\
& & & & & & & \\
\hline
\end{tabular}

Uprating performed using mean wage changes, a1 and a2 reported in Table 1

We begin our analysis by calculating the 'actual' 2008, 2010 and 2013 disposable income distributions. To arrive at the 2008 disposable income distribution (scenario 0 or $\left.d_{0}\left(p^{0}, y^{0}\right)\right)$ the tax benefit model is used to compute taxes paid and benefits received based on the 2008 population with its corresponding gross income distribution and the 2008 taxbenefit rules. The 2010 disposable income distribution (scenario 4 or $d_{1}\left(p^{1}, y^{1}\right)$ ) is arrived at in the same way, this time using the 2010 gross income data and 2010 tax-benefit rules. As we do not have 2013 data we estimate the 2013 'actual' disposable income distribution by uprating the 2010 nominal gross income to 2013 values, using the uprating factor $\alpha^{2}$ (see Table 1), i.e., the wage growth rate between 2010 and 2013. We then apply the 2013 tax-benefit policies to these incomes (scenario 6 or $d_{2}\left(p^{2}, \alpha^{2} y^{1}\right)$ ).

To perform our first decomposition, we construct two counterfactual income distributions, $d_{0}\left(\alpha^{1} p^{0}, \alpha^{1} y^{0}\right)$ and $d_{0}\left(\alpha^{1} p^{0}, y^{1}\right)$ (scenarios 1 and 2 in table 3$)$. These scenarios use the uprating factor $\alpha^{1}$ (see Table 1) to uprate 2008 policy parameters to 2010. We then apply these tax benefit rules to the uprated 2008 gross income distribution for scenario 1 and the 2010 gross income distribution for scenario 2.

This allows us to perform our first decomposition in which the policy effect is evaluated while holding the population constant at the intermediate year (2010).

$$
\begin{array}{rlrl}
\Delta= & \left\{I\left[d_{1}\left(p^{1}, y^{1}\right)\right]-I\left[d_{0}\left(\alpha^{1} p^{0}, y^{1}\right)\right]\right\} & \text { (policy effect) } \\
& +\left\{I\left[d_{0}\left(\alpha^{1} p^{0}, y^{1}\right)\right]-I\left[d_{0}\left(\alpha^{1} p^{0}, \alpha^{1} y^{0}\right)\right]\right\} & & \text { (other effects) } \\
& \left.+\left\{I\left[d_{0}\left(\alpha^{1} p^{0}, \alpha^{1} y^{0}\right)\right)\right]-I\left[d_{0}\left(p^{0}, y^{0}\right)\right]\right\} & & \text { (income growth) } .
\end{array}
$$


We next simulate a further counterfactual income distribution, scenario 3 or $d_{1}\left(p^{1}, \alpha^{1} y^{0}\right)$. This scenario holds the market income distribution constant by uprating 2008 gross incomes to 2010 using $\alpha^{1}$. This is used in a second decomposition in which the policy effect is evaluated while holding the population constant at the base year.

$$
\begin{aligned}
\Delta= & \left\{I\left[d_{1}\left(p^{1}, y^{1}\right)\right]-I\left[d_{1}\left(p^{1}, \alpha^{1} y^{0}\right)\right]\right\} & & \text { (other effects) } \\
& +\left\{I\left[d_{1}\left(p^{1}, \alpha^{1} y^{0}\right)\right]-I\left[d_{0}\left(\alpha^{1} p^{0}, \alpha^{1} y^{0}\right)\right]\right\} & & \text { (policy effect) } \\
& \left.+\left\{I\left[d_{0}\left(\alpha^{1} p^{0}, \alpha^{1} y^{0}\right)\right)\right]-I\left[d_{0}\left(p^{0}, y^{0}\right)\right]\right\} & & \text { (income growth) } .
\end{aligned}
$$

Since there is no compelling reason for preferring the first decomposition over the second, we also compute the Shorrocks-Shapley decomposition by averaging the contributions for the two decompositions above, which gives the average policy effect, $P$, and the average other effect, $O$ between the base and intermediate periods. ${ }^{14}$

$$
\begin{aligned}
& P=1 / 2 *\left[I\left[d_{1}\left(p^{1}, y^{1}\right)\right]-I\left[d_{0}\left(\alpha^{1} p^{0}, y^{1}\right)\right]\right]+1 / 2 *\left[I\left[d_{1}\left(p^{1}, \alpha^{1} y^{0}\right)\right]-I\left[d_{0}\left(p^{0}, y^{0}\right) \amalg I I\right)\right. \\
& O=1 / 2 *\left[I\left[d_{0}\left(\alpha^{1} p^{0}, y^{1}\right)\right]-I\left[d_{0}\left(p^{0}, y^{0}\right)\right]\right]+1 / 2 *\left[I\left[d_{1}\left(p^{1}, y^{1}\right)\right]-I\left[d_{1}\left(p^{1}, \alpha^{1} y^{0}\right)\right]\right] .
\end{aligned}
$$

Recall that we cannot perform the full decomposition for the 2010 to 2013 period due to data constraints. We can, however, calculate a "policy effect" for 2010-13 by defining a final counterfactual disposable income distribution, $d_{2}\left(\alpha^{2} p^{1}, \alpha^{2} y^{1}\right)$ or scenario 5 , which uprates 2010 gross incomes and policy parameters by wage growth during the period, $\alpha^{2}$. The policy effect between 2010 and 2013 can then be estimated:

$$
\begin{aligned}
\Delta= & \left\{I\left[d_{2}\left(p^{2}, \alpha^{2} y^{1}\right)\right]-I\left[d_{1}\left(\alpha^{2} p^{1}, \alpha^{2} y^{1}\right)\right]\right\} \quad \text { (policy effect) } \\
& \left.+\left\{I\left[d_{1}\left(\alpha^{2} p^{1}, \alpha^{2} y^{1}\right)\right)\right]-I\left[d_{1}\left(p^{1}, y^{1}\right)\right]\right\} \quad \text { (income growth) } .
\end{aligned}
$$

\subsubsection{Homogenity Check}

Notice that tax-benefit functions $d(p, y)$ are usually linearly homogeneous in $p$ and $y$, i.e. a simultaneous change in nominal levels (e.g. switching from Pounds Sterling to Euro) of both gross incomes and monetary tax-benefit parameters should not affect the relative position of households in the distribution of disposable income. The direct consequence

\footnotetext{
${ }^{14}$ The general Shorrocks-Shapley decomposition method has been applied in several contexts, including the decomposition of changes in inequality trends (see Mookherjee and Shorrocks, 1982, for the UK and Cowell and Jenkins, 1995, for the US), in poverty trends (Kolenikov and Shorrocks, 2005) and in income mobility indices (van Kerm, 2004). Jenkins and van Kerm (2005) also analyse inequality changes in the UK in the 1980s and discuss the choice of weights used in the decomposition, either base-period values, end-period values or the Shapley value.
} 
of this is that inequality and poverty measures calculated using the disposable income distribution of scenario (0) i.e. applying the 2008 tax-benefit rules to the 2008 data, should be equal to scenario (1) in which the uprated 2008 tax-benefit parameters are applied to the uprated 2008 data. That is, the 'income growth' component, the third term in decompositions I and II above, should be zero. ${ }^{15}$ A second homogenity check is also possible by comparing the inequality and poverty statistics calculated using the disposable income distributions from scenario 4 (2010 tax-benefit rules applied to 2010 data) and scenario 5 (i.e. 2010 tax-benefit rules uprated to 2013 and applied to 2010 data uprated to 2013). We check this empirically in the next section.

\section{Results}

Tables A.2 to A.5 in Appendix A.3 present complete decomposition results for France, Germany, Ireland and the UK respectively as well as the homogenity checks. The main results, however, are summarised in Figure 3. In each panel in this figure, inequality and poverty indices are reported with reference to the base period value (2008 in the first three panels and 2010 in the last panel) which is normalised to 100 and represented by the dashed black line for comparison. Inequality is measured by the Gini index and a range of poverty measures are also shown. The poverty headcount index (FGT0) shows the proportion of the population who have equivalised disposable income at or below $60 \%$ of the median. Poverty depth, estimated using the FGT1 index, measures how far individuals are from the poverty line. Poverty rates for subgroups of the population (households containing children, households headed by individuals over 60 years of age, working households, non-working households, etc) are also reported. The top panel in Figure 3 shows the total change in the inequality and poverty indices between 2008 and 2010. The second and third panels of Figure 3 show the Shorrocks-Shapley decomposition (equation III) of the total change 2008-10 into a "policy" effect and an "other" effect. The second panel shows the hypothetical change in inequality and poverty measures between 2008-10 in the absence of policy changes, i.e. this graph isolates changes that are due to effects other than tax-benefit policy such as changes in incomes, job losses etc. The third panel shows what inequality and poverty measures would have looked like if the only changes to occur were policy changes and the underlying gross income distribution had remained unchanged between 2008 and 2010. The final panel of Figure 3 shows the effect of policy between 2010 and 2013 on poverty and inequality using the decomposition

\footnotetext{
${ }^{15}$ While this should be the case in France, Ireland and the UK, part of the German system may not fulfill this condition. Germany is characterized by a concave income tax function, in contrast to the piecewise linear income tax schedule of other countries and, therefore, a non-homogenous tax-benefit function.
} 
elaborated in equation IV.

In interpreting each panel of the graph, if the relevant bar is above the dashed line then the inequality/poverty meaure rose due to the relevant change (policy/other) over the period concerned. If it is below the dashed line then the inequality/poverty meaure fell. If the bar is at the dashed line then the measure remained unchanged.

\subsection{France}

Inequality slightly increased between 2008 and 2010 in France due to market income shocks while policy effects left inequality measures unchanged. Subsequent policy changes after 2010, however, decreased inequality. A similar pattern emerges on examining relative poverty measures. Between 2008 and 2010, relative positions of the poorest deteriorate due entirely to a strong shock to their market income, reflecting how increasing unemployment has affected the lower part of the income distribution. This trend is reversed by policy reforms after 2010 .

Turning to "absolute" poverty changes, i.e. when fixing the poverty line at a constant level in real (income inflation adjusted) terms, we find that, despite negative market income shocks, the standard of living of the poor has remained relatively stable between 200813 thanks to policy effects in the period 2008-10 such as the introduction of an in-work benefit component to the French minimum income scheme. However, subsequent policy reforms between 2010-13, namely, the failure of income tax or or social security thresholds to keep pace with rising wages, have slighty increased absolute poverty once again.

Among the sub-groups studied, patterns for children, the working poor and the working poor with children are similar over the time period studied. Although market shocks between 2008 and 2010 increased child poverty, policy reforms over the entire period 2008-13 have worked to counteract this increase. The same can be said for working poverty and working poverty with children. Elderly poverty was pushed up slightly by policy reforms between 2008-10 but decreased again from 2010 onwards thanks to further policy reforms. Non-working families with children have higher poverty levels in 2010 due to the failure of social assistance to keep pace with wage increases. This trend is reversed after 2010 with incerases in child benefit payments and reforms to education benefits.

\subsection{Germany}

Inequality was little affected by either policy or market effects between 2008-13 in Germany. However, a decline in the relative position of those at the bottom of the distribution is illustrated by the poverty measures. Headcount ratio poverty, with a relative poverty 
Figure 3: Decomposing Inequality/Poverty Change: International Comparison
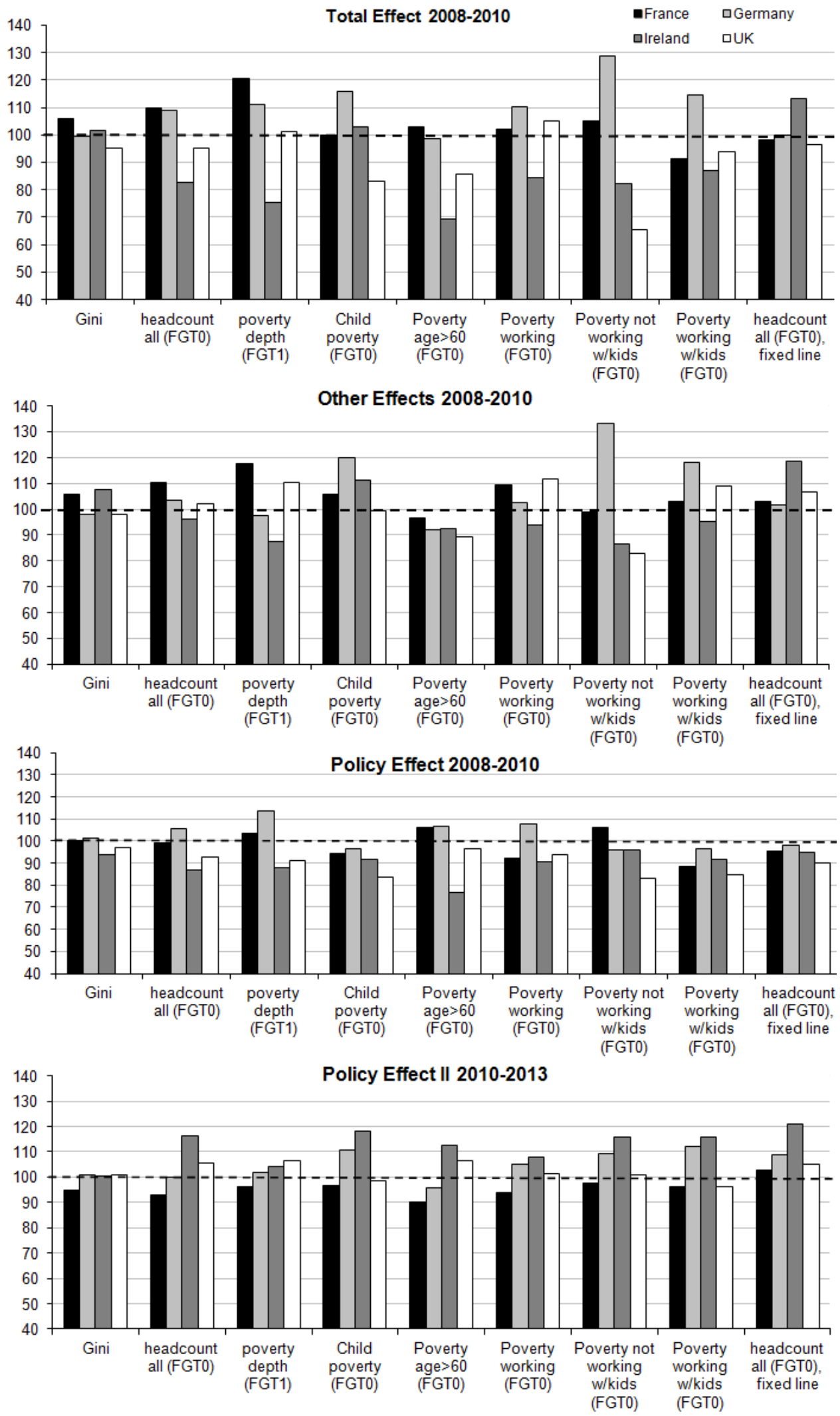
line set at $60 \%$ of the median, increased between 2008 and 2010 due both to policy and to other effects. While relative poverty remained stable from 2010 onwards, absolute poverty continued to increase after 2010. The overall poverty increases until 2010 can be attributed to the slow uprating of social assistance, the decrease in tax allowances and the change in capital income taxation. After 2010, the failure of income tax and social security bands to keep up with market income increases makes those on low incomes relatively poorer, increasing the depth of poverty and absolute poverty rate.

Turning to subgroups of the population, we find an increase in child poverty, working poverty, working poverty with children and, in particular, non-working poverty with children between 2008-10. These increases can be attributed to market income changes. With the exception of working poverty, there are small opposing policy effects for the period 2008-10 which are likely to be attributable to increases in child benefits and education allowances. However, from 2010 onwards many of these policy trends are reversed with increases in the poverty rate of households with children, working and non-working households notable between 2010 and 2013. Poverty rates of the elderly decrease in both periods examined but while the decrease between 2008-10 can be attributed to market shocks, the decrease after 2010 is due to policy changes.

\subsection{Ireland}

Overall inequality was relatively unchanged in Ireland between 2008 and 2010. This was due to the fact that policy reforms worked to decrease inequality compared to what could

have been expected in the context of massive job losses. (see also O'Donoghue et al., 2013). Policy reforms after 2010 have had little effect on inequality. Our simulations show a consistent decrease in all poverty measures excluding child poverty between 200810. These early poverty decreases can be attributed both to policy and other effects. Patricularly for the elderly, poverty rates fell due to policy changes such as increases in social welfare rates in 2009, a policy which was counteracted by reductions in 2010 for all but the elderly. The overall rise in child poverty between 2008-10 was small due to the cushioning effect of policy. However, subsequent policy reforms increased child poverty rates, along with all other reported measures of poverty after 2010. This increase in poverty after 2010 is the result of continuing and heavy austerity measures. As mentioned in Section 2.2 and described in Appendix A.2, the universally paid Child Benefit rates were cut sharply between 2010-13, particularly for larger households, with no increase in payments for child dependants of social welfare recipients. Unemployment benefits and welfare payments to one-parent families were also reduced.

Looking lastly at absolute poverty rates, we find that they increase in both periods 
examined. Between 2008-10, this increase can be attributed to market shocks. However, between 2010-13, austerity begins to bite and the policy reforms described above lead to a large increase in the absolute poverty rate.

\subsection{UK}

Inequality decreased in the UK between 2008-10 and was stable thereafter. This was driven by a combination of tax-benefit policy reforms and market income changes between 2008-10. The headcount index also decreased while the depth of poverty actually increased slightly between 2008-10. Both of these changes were the result of a combination of poverty-reducing policies, such as the uprating of benefits and the working tax credit and the lower standard tax rate, and poverty-increasing other effects. Similar policy and other trends are also reflected in the small decrease in absolute poverty before 2010.

Within subgroups, we note large decreases in the poverty rates of children, the elderly and those working and not working with children. These decreases are, in large part, fuelled by policy changes between 2008-10; increases in child benefit rates ( $+8 \%$ between 2008 and 2010) and increases in child tax credits. ${ }^{16}$ Market income changes up to 2010 also contributed to the decrease in elderly poverty and non-working with children poverty. We can expect no large changes to poverty due to more recent policy changes. The headcount ratio is slightly increased by policy changes between 2010 and 2013 although there is heterogeneity across groups. Child poverty and working and non-working poverty with children increase due to the abolishment of the child benefit for those earning over $£ 50,000$, the decrease in the proportion of childcare costs eligible for reimbursement and new housing allowance restrictions. Meanwhile, working poverty decreases due to the large increase in social security thresholds; in the child tax credit and in personal tax allowances, coupled with the increase in the starting threshold for the $20 \%$ income tax rate.

\section{Concluding Discussion}

This paper examined the impact on inequality and poverty of the Great Recession in France, Germany, Ireland and the UK. Using microsimulated counterfactuals, we decompose changes in inequality and poverty measures between 2008 and 2010 into the contribution of tax-benefit policy changes and all other factors, notably those impacting on gross income distributions because of the crisis (job losses, reduced work hours, wage cuts) or because of other, non-simulated policies (e.g. minimum wage changes etc.).

\footnotetext{
${ }^{16}$ These decreases in child related poverty rates are in line with findings in Brewer et al (2013).
} 
In a further, partial decomposition, we then isolate the change inequality and poverty measures between 2010 and 2013 which is due to tax-benefit policy changes.

Comparing policy and other effects for all countries, unveils very contrasted trends. Maybe counter to intuition, the country most affected by the economic turmoil, Ireland, implemented a strong and very progressive set of policy responses between 2008-2010 resulting in little change in inequality and declines in relative poverty rates. To a large extent, this policy response served to offset the rise in inequality and child poverty which would have arisen from changes in unemployment and market income in the early part of the recession. Estimates of the policy impact of tax-benefit changes between 2010 and 2013, however, have worked in the opposite direction and have slightly increased inequality and substantially increased poverty rates in Ireland.

Another unexpected result is the relatively regressive initial policy response in Germany. Between 2008 and 2010 the poverty rate and depth rose in Germany, driven largely by policy effects. Meanwhile, policy changes between 2010 and 2013 have continued to increase the poverty rates of specific groups in German society such as the working and workless poor with children. While the period under investigation is too short to draw conclusions regarding a change in the German social model, the years 2008-2013 have, nonetheless, witnessed a combination of regressive tax policy and slow uprating of social benefits for the poorest and these are responsible for increased relative poverty in this country.

France saw a rise in inequality and overall poverty rates between 2008 and 2010, due mainly to non-policy effects such as job losses and wage cuts. Falls in inequality and poverty during the same period in the UK are attributable to policies such as tax cuts and benefit increases. Policies enacted in the later years of the recession (2010-2013) are inequality and poverty reducing in France while mixed results across subsamples of the population are observed in the UK.

These results are not necessarily in line with the impression of the degree of public spending cuts given by the media during the crisis. In particular, the UK government was accused of making overly large public spending cuts during the Great Recession. However, overall inequality and poverty have not suffered the increases one might expect if this were the case. This is an important finding for countries who continue to experience a need for budgetary prudence and offers hope for governments needing to implement austerity measures. These do not necessarily need to be inequality and poverty increasing if carried out effectively. Public opinion in Ireland has also be critical of the heavy austerity measures implemented to tackle the crisis. However, these measures actually helped to stabilise relative and absolute poverty in the first half of the crisis and prevented large increases in inequality over the entire period. Our results also suggest that a change in the 
German social model may be underway. Signs of this change were already evident with wage moderation in the nineties, followed by the Hartz IV reforms in the noughties which tightened access to social welfare. The current regressive policy management of the crisis suggests that Germany may be moving further away from its traditional classification as a conservative/corporate welfare regime.

Overall, a general conclusion from our analysis is that tax-benefit policy effects have had a very important role, sometimes larger than the shock on market incomes due to the crisis. For instance, policy effects explain much of the relative poverty increase in Germany and of the decline in relative poverty in Ireland between 2008 and 2010. On a general note, some of the major measures that we saw implemented in the four countries studied concerned means testing benefits which had previously been universal. The effects of this shift towards incentivising work and penalising inactivity may be felt long after the end of the Great Recession.

\section{References}

[1] Bargain, O., 2012. "The distributional effects of tax-benefit policies under New labor: A Shapley decomposition", Oxford Bulletin of Economics and Statistics, 74(6), 856-874

[2] Bargain, O. \& Callan, T., 2010. "Analysing the effects of tax-benefit reforms on income distribution: a decomposition approach," Journal of Economic Inequality, Springer, 8(1), 1-21.

[3] Bargain, O., H. Immervoll, A. Peichl, S. Siegloch, 2012: "Distributional consequences of labor-demand shocks: the 2008-2009 recession in Germany", International Tax and Public Finance, 19 (1), 118-138

[4] Brenke, K., Rinne, U. \& Zimmermann, K., 2011. "Short-Time Work: The German Answer to the Great Recession," IZA Discussion Papers 5780, Institute for the Study of Labor (IZA).

[5] Brewer, M.\& Browne, J. \& Hood, A. \& Joyce, R. \& Sibieta, L., 2013. "The Shortand Medium-Term Impacts of the Recession on the UK Income Distribution," Fiscal Studies, Institute for Fiscal Studies, 34(2).

[6] Burda, M. \& Hunt, J., 2011. "What Explains the German Labor Market Miracle in the Great Recession," Brookings Papers on Economic Activity, Economic Studies Program, The Brookings Institution, 42(1), 273-335.

[7] Callan, T. \& Keane, C. \& Savage, M. \& Walsh, J., 2012. "Distributional Impact of 
Tax, Welfare and Public Sector Pay Policies: 2009-2012," Quarterly Economic Commentary: Special Articles, ESRI, vol. 2012(4-Winter ).

[8] Clark, T. \& Leicester, A., 2004. "Inequality and two decades of British tax and benefit reform", Fiscal Studies, 25 (2): 129-158.

[9] Dardanoni, V. \& Lambert, P., 2002. "Progressivity comparisons", Journal of Public Economics, 86, 99-122.

[10] De Agostini, P., Paulus, A., Sutherland, H. and Tasseva, I. (2014). "The effect of taxbenefit changes on the income distribution in EU countries since the beginning of the economic crisis" EUROMOD Working Paper No. EM 9/14.

[11] Doorley, K., 2013. "EUROMOD Country Report France, 2009-2012"

[12] Doorley, K., Eichhorst, W. \& Kendzia, M., 2013."Report No. 52: The Social and Employment Situation in Ireland (Update February 2013),"IZA Research Reports 52 , Institute for the Study of Labor (IZA).

[13] Esping-Andersen, G.1990. The three worlds of welfare capitalism. Cambridge: Polity Press

[14] Hardiman, N. (2006), 'Politics and Social Partnership: Flexible Network Governance', Economic and Social Review, Vol. 37, no. 3, pp. 343-74.

[15] Jenkins, S. P. (1995): .Accounting for Inequality Trends: Decomposition Analyses for the UK, 1971- 86., Economica, 62, 245, 29-63.

[16] Jenkins, S. and P. van Kerm (2005) .Accounting for income distribution trends: A density function decomposition approach., Journal of Economic Inequality, $3(1), 43-61$.

[17] Jenkins, S., Brandolini, A., Micklewright, J. \& Nolan, B. (eds), 2013 "The Great Recession and the Distribution of Household Income", UK: Oxford University Press.

[18] Joyce, R. and Levell, P. (2011) "The impact in 2012-13 of the change to indexation policy", Institute for Fiscal Studies Briefing Note 120.

[19] Keane, C., Kelly, E., Timoney, K. \& Callan, T., 2013. "EUROMOD Country Report: Ireland, 2009-2012"

[20] Kolenikov, S. and A. Shorrocks (2005): .A Decomposition Analysis of Regional Poverty in Russia., Review of Development Economics, 9, 1, 25-46.

[21] Lambert, P. \& Thoresen, T., 2009. "Base independence in the analysis of tax policy effects: with an application to Norway 1992-2004", International Tax and Public Finance, 16, 219-252. 
[22] Matsaganis, M. \& Leventi, C., 2014, "Distributive Effects of the Crisis and Austerity in Seven EU Countries," ImPRovE Working Papers 14/04, Herman Deleeck Centre for Social Policy, University of Antwerp.

[23] McLaughlin, E., 1993. "Ireland: Catholic Corporatism" in, A. Cochrane and J. Clarke (eds) Comparing welfare states: Britain in international context. London: Sage

[24] Mookherjee, D. and A.F Shorrocks (1982): "A decomposition analysis of the trend in UK income inequality", Economic Journal, 92(368), 886.902

[25] Ochmann, R. \& Fossen, F., 2012. "EUROMOD Country Report Germany, 2009$2012^{\prime \prime}$

[26] O’Donoghue, C., J. Loughrey \& K. Morrissey, 2013. "Using the EU-SILC to Model the Impact of the Economic Crisis on Inequality", IZA Discussion Paper No. 7242

[27] Schlenker, E. and Schmid, K. (2013), "Capital Income Shares and Income Inequality in the European Union", Macroeconomic Policy Institute Working Paper.

[28] Sutherland, H., 2013. "EUROMOD Country Report UK, 2009-2012"

[29] van Kerm, P. (2004): "What Lies Behind Income Mobility? Reranking and Distributional Change in Belgium, Western Germany and the USA", Economica, 71, 223.239 . 